\title{
Theory Building for the Profession of Teacher Librarianship: An Application of Meta-Ethnography
}

\author{
Nancy Everhart, Ph.D. \\ Florida State University, USA
}

\author{
Melissa P. Johnston, Ph.D. \\ University of West Georgia, USA
}

\begin{abstract}
The lack of theoretical foundations for research in the field of library and information science is well documented and leads researchers to borrow from other fields. In the case of school library research, the tendency is to borrow from the field of education. While many theories from education and other disciplines are applicable to school library research, there needs to be development of theory among school library researchers in order to give practitioners understanding of the complex relationships involved in school libraries and guide future research efforts. Meta-ethnography uses findings reported in previous studies as building blocks for gaining deeper understanding of a particular phenomenon and is highly applicable for the initial stages of theory development. This paper provides a thorough description of the meta-ethnography method and an example of how meta-ethnography can be applied for theory building in school library research.
\end{abstract}

\section{Keywords: School Libraries, Meta-ethnography, Theory \\ INTRODUCTION TO THE PROBLEM}

The critical need for theoretical foundations in the library and information science (LIS) profession is well documented (e.g., Grover \& Glazier, 1986; Hjørland, 1998; Julien \& Duggan, 2000; Julien, Pecoskie, \& Reed, 2011; Leckie, Given, \& Buschman, 2010; MeKechnie \& Pettigrew, 2002; Pettigrew \& McKechnie 2001). A theoretical foundation helps define a discipline and is necessary "for framing research problems, building arguments, and interpreting empirical results" (Pettigrew \& McKetchnie, 2001, p. 62). Theory is also "an important element for establishing the identity of LIS" (Kim \& Jeong, 2006, p. 549) and yet there has been little attention paid to theory in the literature of the field and there is even a decline in theory use and development (Julien \& O'Brien 2011; Kim \& Jeong, 2006). This decline in theory development may represent a trend in LIS research to utilize "existing theory rather than to generate new theories" (Kim \& Jeong, 2006, p. 559). This study utilizes meta-ethnography to develop a theory of teacher librarian leadership.

\section{REVIEW OF RELEVANT LITERATURE}

Since the discipline of library and information studies is principally defined as a social science, and ethnography is employed for social understanding (Bawden, 2012), it can be posited that ethnographic studies can be useful for theory building in LIS as they are in other social science specialties. Meta-ethnography, a specific form of ethnography developed by George W. Noblit and R. Dwight Hare (1988), enables researchers to understand and synthesize the findings of two or more qualitative studies concerning a similar research question or topic. Mike Weed (2005) has described metaethnography as a form of meta-interpretation. Going beyond the traditional literature review, which looks at individual studies, meta-ethnography facilitates generalizations through extracting concepts, metaphors, and themes (Burns, 1989).

Meta-ethnography is interpretive rather than aggregative, with the goal being to "produce new interpretations of the primary study author's interpretations (e.g., themes, concepts or metaphors) of the research participants' experiences in published primary qualitative studies" (France et al., 2014, para. 4). Also, unique to meta-ethnography is the systematic analysis process designed to preserve the context and 
meanings of the primary studies through utilizing translation, which is "the process through which data are synthesised - it involves continuously comparing the meaning of the concepts from all the primary studies to reach a full understanding of the issues" (France et al., para 4). Noblit and Hare (1988) described it as "making a whole into something more than the parts alone imply" or going beyond the findings of any individual study (p. 28).

\section{APPLICATION TO LIBRARY AND INFORMATION SCIENCE RESEARCH}

As qualitative research has been increasing over the past three decades, particularly in top-ranked Library and Information Science journals (Agosto et. al, 2007), meta-ethnography can provide a useful method for synthesizing this research for new understandings. Some have noted that as a discipline we need to make better use of existing research evidence, instead of conducting yet more small-scale studies (Urquhart, 2011). Library and information science has been criticized for a lack of dialogue, a tendency to develop new models - rather than test the transferability of existing models, overuse of surveys that do not lead to theory, confusion over the paradigms used, and using a narrow lens to examine a problem (Afzal, 2006; Bates, 2005; Dervin, Reinhard, \& Shen, 2006). Meta-ethnography, by reconceptualizing and synthesizing existing research, "compels us to acknowledge the uniqueness of individual cases, but also the uniqueness of collectives" (Urquhart, 2011, p. 38).

It has been posited that since only high quality data are analyzed in a meta-ethnography, it can lead to conclusions on the effectiveness of an intervention and the creation of new understandings (Bawden, 2012; Urquhart, 2011). This is an extremely valuable application of the method for LIS because "unfortunately, randomised controlled trials are not appropriate for answering many of the questions that arise in information behaviour" (Urquhart, 2011, p. 40). Jonathan Lomas (as cited in Shelbe, 2016) pointed to the development of data repositories over a decade ago as a resource in extending synthesis approaches to incorporate viewpoints of a wider spectrum of stakeholders. The increase of university research repositories makes a wide range of unique historical, as well as original, research broadly available in LIS, which can function as sources for meta-ethnography studies.

Meta-ethnography also has implications for research teams. The method is richer when multiple researchers bring various perspectives to the process of reading, summarizing, and bridging summaries. This leads to resulting products that are logical, deductive rationalizations, sound conclusions, and to calls for further research (Doyle, 2003; Toye et al., 2014). Meta-ethnography extends borders by allowing researchers to communicate across fields, which is important in an inter-disciplinary and multi-faceted field like LIS. Shuaib Meacham (1998) argues that today's educational issues and problems cannot be studied in an isolated and homogeneous manner; researchers from multiple disciplines need to be "brought together simultaneously" (p. 405). This can also be a useful exercise for doctoral students. Norman Lincoln and Yvonna Denzin (2000) even suggest that researchers can enhance translations by including the voices of those researched to seek new interpretations. Additionally, when researchers enhance their translations with rich detail and the language of participants, they raise, not mute, the voices of those who are researched.

\section{DESCRIPTION OF THE METHOD}

Noblit and Hare (1988) provide a seven-step process for conducting a meta-ethnography as shown in Figure 1. This method begins with the research idea and takes the researcher through to expressing the findings; each step is described in detail below. The steps are not necessarily discrete, but rather are part of an iterative research process (Toye et al., 2014). 


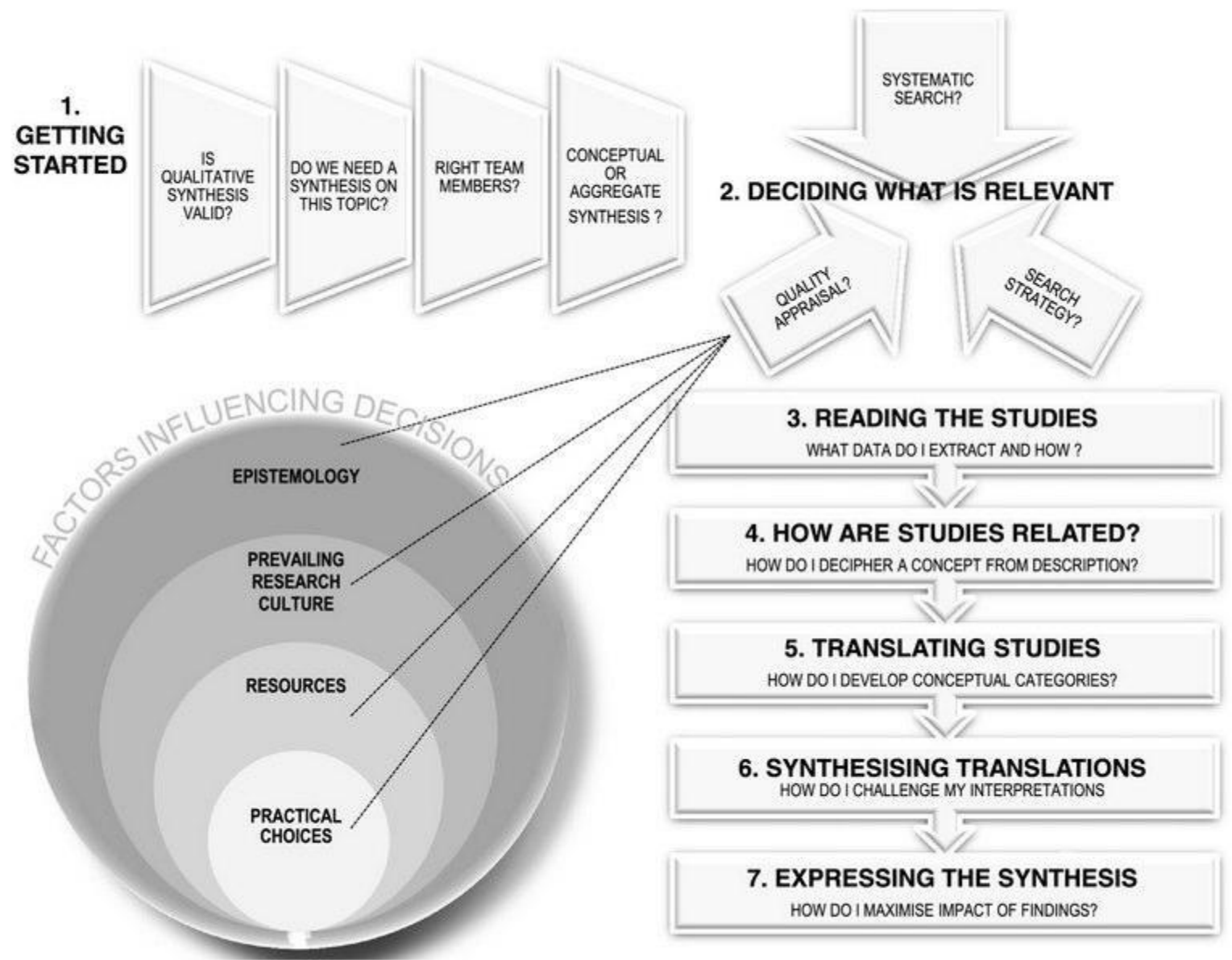

Figure 1. Stages of Meta-ethnography: 1. Getting started; 2. Deciding what is relevant; 3. Reading the studies; 4. Determining how the studies are related; 5. Translating studies into each other; 6. Synthesising translations; 7. Expressing the synthesis (Toye et al., 2014)

\section{APPLICATION OF THE METHOD}

Although a few researchers have maintained that meta-analysis has the potential to make substantive contributions in LIS research (Afzal, 2006, Ankem, 2005; Bawden, 2012; Hjørland, 2001; Shelbe, 2016; Urquhart, 2011), there had not been a study in LIS that applied a meta-ethnographic approach as formulated by Noblit and Hare (1988) until this study. This research provides an example of how meta-ethnography can be applied for theory building in LIS. Meta-ethnography proved to be a rigorous and robust method to develop a conceptual model of teacher librarian leadership for a team of two researchers based on six studies that were relevant to the topic. The meta-ethnography method allowed for the identification of key concepts and the initial explanation of their interdependence. This resulted in five key propositions towards a theory of teacher librarian leadership, which can be seen in Table 1.

Table 1. Results of a Meta-Ethnographic Study of Teacher Librarian Leadership

\begin{tabular}{|l|l|l|l|l|}
\hline $\begin{array}{l}\text { Focus of } \\
\text { Relevant } \\
\text { Studies }\end{array}$ & Concepts & $\begin{array}{l}\text { Second-Order } \\
\text { Interpretations }\end{array}$ & $\begin{array}{l}\text { Third-Order } \\
\text { Interpretations }\end{array}$ & Propositions \\
\hline Developing a & Resistance: to & Teacher librarians & Teacher librarian & Education can \\
\hline
\end{tabular}




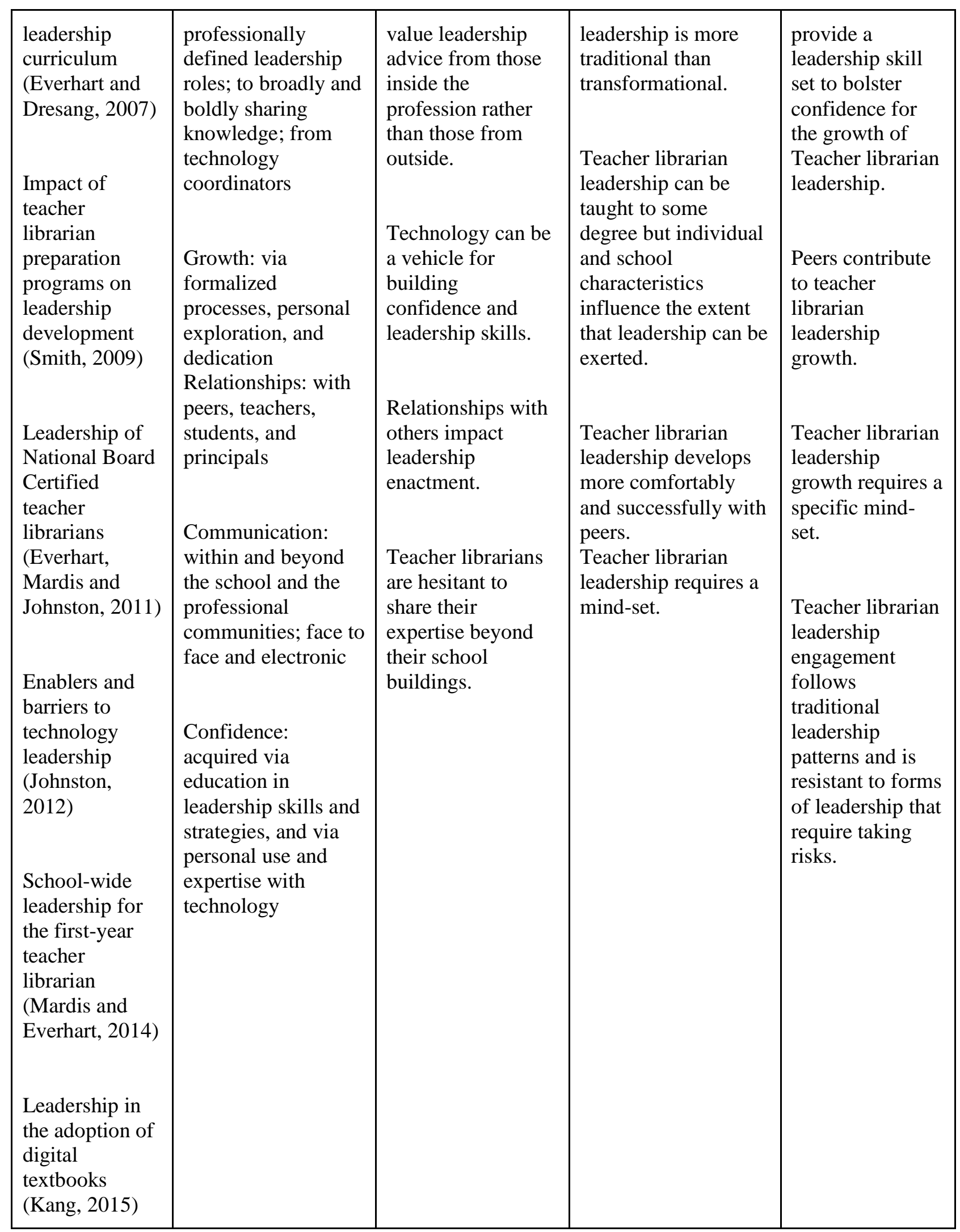


The concepts and propositions derived from the meta-ethnographic exercise developed into a conceptual model (see Figure 2) to express the synthesis.

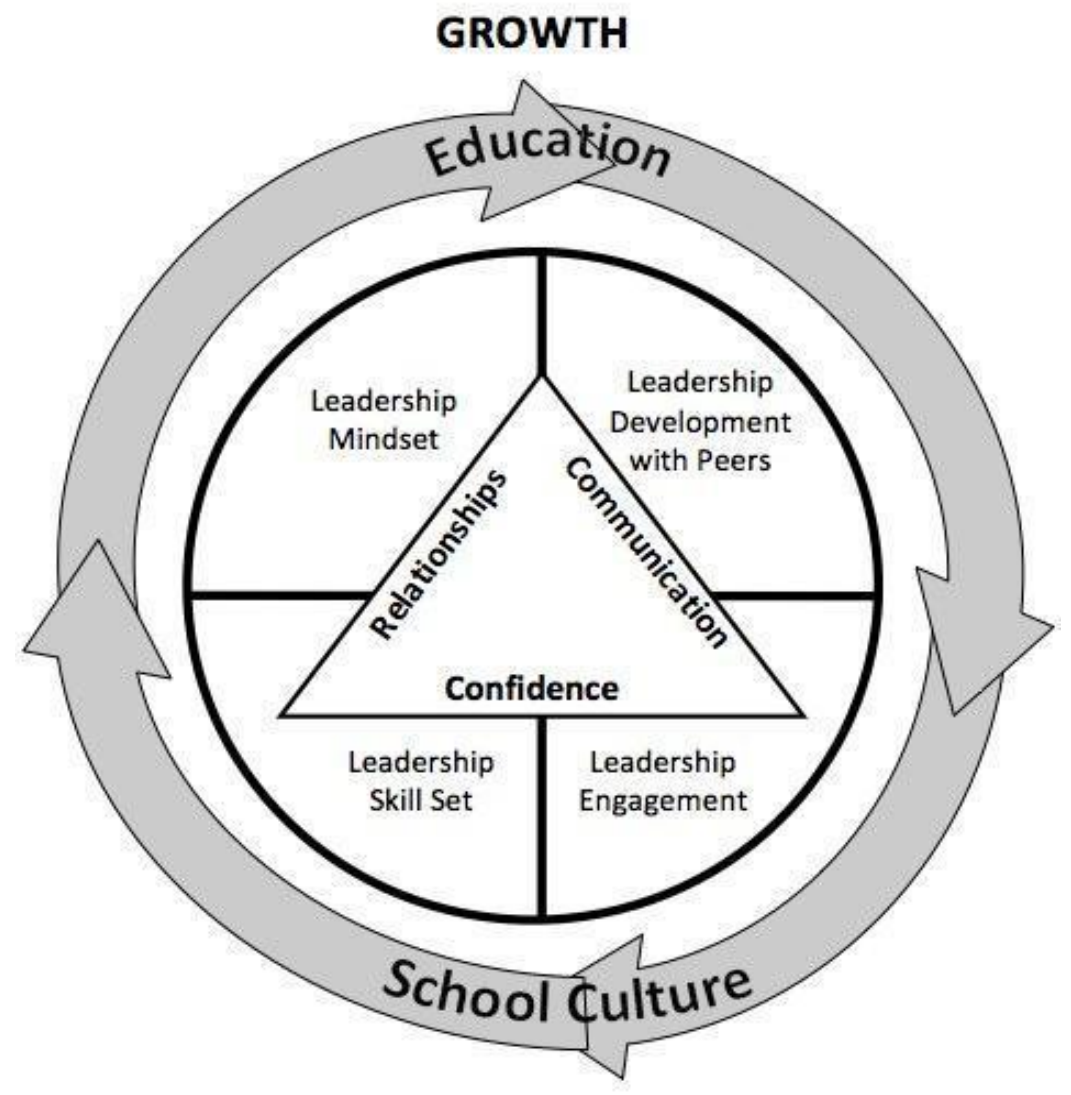

RESISTANCE

Figure 2. Conceptual model of teacher librarian leadership.

\section{FINDINGS AND DISCUSSION}

Phase one of developing a conceptual model begins with conceptual development, which requires the formulation of "initial ideas in a way that depicts current, best, most informed understanding and explanation of the phenomenon, issue, or problem in the relevant world context" (Lynham 2002, p. 231). "The output of this phase is an explicit, informed, conceptual framework that often takes the form of a model and/or metaphor that is developed from the theorist's knowledge of and experience with the phenomenon, issue, or problem concerned" (Lynham 2002, p. 232).

Laura Sheble (2016) recently echoed the thoughts of Hjørland (2001) from over a decade ago that research synthesis has been neglected in LIS literature. Sheble presents a detailed comparison of the differences in the steps in conducting research synthesis and a metaethnography, asserting that meta-ethnography is a more developed and interpretive approach. Keeping the defined differences in mind that differentiate research synthesis from metaethnography, there had not been a study in LIS that applied a meta-ethnographic approach as formulated by Noblit and Hare (1988) until this one. This research provides an example of how meta-ethnography can be applied for theory building in LIS. The output for this first phase of theory building is a research-informed conceptual model (Lynham, 2002). Our model is based on 
flexible conceptual terms rather than rigid theoretical variables and causal relations, and can, therefore, be modified with the evolution of teacher librarian leadership or as a result of new research. This conceptual model aims to help educators understand the phenomenon of teacher librarian leadership rather than to predict it.

\section{CONCLUSION}

Use of synthesis methods such as meta-ethnography "is an important development for library and information science researchers and practitioners because it has affected how researchers in other fields interact with literature, data, and information infrastructures" (Sheble, 2016, p. 1990). Opportunities arise from "undiscovered public knowledge" (Swanson, 1986, p. 104) and the ability to synthesize across research studies for the purpose of contributing to theory development (Glaser \& Strauss, 1971; Grover \& Glazier, 1986). Our utilization of meta-ethnography for theory building in LIS provides a model and proof-in-concept for other researchers. Further studies are needed to support this theory-in-progress once the results have been disseminated.

In the next phase of theory building, the proposed model, concepts, and propositions need to be confirmed and/or tested in real-world contexts. We propose this conceptual model as a starting point and believe that this model and the propositions emerging from it provide an agenda for future research. Therefore, to contribute to further developing a theory of teacher librarian leadership to inform and improve practice, future research investigating and testing the propositions in the real-world context of teacher librarianship is planned.

\section{REFERENCES}

Afzal, W. (2006). An argument for the increased use of qualitative research in LIS. Emporia State Research Studies, 43(1), 22-25.

Agosto, D., Shanshan, M., \& Yen, B. (2007). Qualitative trends in library \& information science (LIS) research. Retrieved from http://hdl.handle.net/1860/1588

Ankem, K. (2005). Approaches to meta-analysis: A guide for LIS researchers. Library \& Information Science Research, 27(2), 164-176.

Bawden, D. (2012). On the gaining of understanding: syntheses, themes and information analysis. Library and Information Research, 36(112), 147-162.

Bates, M. J. (2007). What is browsing-really? A model drawing from behavioural science research. Information Research, 12(4). Retrieved from http://InformationR.net/ir/12-4/paper330.html

Burns, N. (1989). Standards for qualitative research. Nursing Science Quarterly, 2(1), 44-52.

Dervin, B., Reinhard, C. D., \& Shen, F. C. (2006). Beyond communication: research as communicating. Making user and audience studies matter. Information Research, 12(1). Retrieved from http://InformationR.net /ir/12-1/paper287.html

Doyle, L. (2003). Synthesis through meta-ethnography: paradoxes, enhancements, and possibilities. Qualitative Research, 3(3), 321-344.

Everhart, N., \& Dresang, E. T. (2007). Integrating research results and national board certification standards into a leadership curriculum for school library media specialists. Journal for Education in Library and Information Science, 48(4), 271-283.

Everhart, N., Mardis, M., \& Johnston, M. P. (2012). National board certified school librarians' leadership in technology integration: Results of a national survey. School Library Media Research, 14(1). Retrieved from http://www.ala.org/aasl/slr

France, E. F., Ring, N., Thomas, R., Noyes, J., Maxwell, M., \& Jepson, R. (2014). A methodological systematic review of what's wrong with meta-ethnography reporting. BMC Medical Research Methodology, 14(119). Retrieved from https://bmcmedresmethodol.biomedcentral.com/ articles/10.1186/1471-2288-14-119 
Glaser, B. G., \& Strauss, A. L. (1971). Status passage: A formal theory. Chicago, IL: Aldine.

Grover, R., \& Glazier, J. (1986). A conceptual framework for theory building in library and information science. Library and Information Science Research, 8(3), 227-42.

Hjørland, B. (1998). Theory and metatheory of information science: A new interpretation. Journal of Documentation, 54(5), 606-21.

Hjørland, B. (2001). Why is meta-analysis neglected by information scientists? Journal of the American Society for Information Science and Technology, 52(13), 1193-1194.

Johnston, M. P. (2012). School librarians as technology integration leaders: Enablers and barriers to leadership enactment. School Library Research, 15(1). Retrieved from http://www.ala.org/aasl/slr

Julien, H., \& Duggan, L. J. (2000). A longitudinal analysis of the information needs and uses literature. Library and Information Science Research, 22(3), 291-309.

Julien, H., \& O'Brien, M. (2014). Information behavior research: Where have we been, where are we going? Canadian Journal of Information and Library Science, 38(4), 239-250.

Julien, H., Pecoskie, J., \& Reed, K. (2011). Trends in information behavior research, 1999-2008: A content analysis. Library \& Information Science Research, 33(1), 19-24.

Kang, J. H. (2015). The Leadership Role of School Librarians in the Adoption of Digital Textbooks: Evaluating School Librarians' Stages of Concern in Florida and South Korea. Doctoral dissertation, Florida State University.

Kim, S., \& Jeong, D. Y. (2006). An analysis of the development and use of theory in library and information science research. Library and Information Science Research, 28(4), 548-562.

Leckie, G. J., Given, L. M., \& Buschman, J. E. (Eds). (2010). Critical theory for library and information science: Exploring the social from across the disciplines. Santa Barbara, CA:

Libraries Unlimited.

Lincoln, Y. S., \& Denzin, N. K. (2000). The seventh moment: Out of the past. In N. K. Denzin \& Y. S. Lincoln (Eds.), Handbook of Qualitative Research (pp. 1047-65). Thousand Oaks, CA: Sage.

Lynham, S. A. (2002). General method of theory building in applied disciplines. Advances in Developing Human Resources, 4(3), 221-41.

Mardis, M., \& Everhart, N. (2014). Stakeholders as researchers: A multiple case study of using cooperative inquiry to develop and document the formative leadership experiences of new school library professionals. Library and Information Science Research, 36(1), 3-15.

McKechnie, L., \& Pettigrew, K. E. (2002). Surveying the use of theory in library and information science research: A disciplinary perspective. Library Trends, 50(3), 406-417.

Meacham, S. J. (1998). Threads of a new language: A Response to Eisenhart's on the subject of interpretive review. Review of Educational Research, 68(4), 401-408.

Noblit, G. W., \& Hare, R. D. (1988). Meta-ethnography: Synthesizing qualitative studies. Newbury Park, CA: Sage.

Pettigrew, K. E., \& McKechnie, L. (2001). The use of theory in information science research. Journal of the American Society for Information Science and Technology, 52(1), 62-73.

Sheble, L. (2016). Research synthesis methods and library and information science: Shared problems, limited diffusion. Journal of the Association for Information Science and Technology, 67(8), 1990-2008.

Smith, D. (2009). Self Perceptions of Leadership Potential: A Study of Teacher-Leaders Educated to be School Library Media Specialists Who Lead. Doctoral dissertation, Florida State University.

Swanson, D. R. (1986). Undiscovered public knowledge. Library Quarterly, 56(2), 103-118.

Toye, F., Seers, K., Allcock, N., Briggs, M., Carr, E., \& Barker, K. (2014). Meta-ethnography 25 years on: Challenges and insights for synthesising a larger number of quantitative studies. $B M C$ 
Medical Research Methodology, 14(80). Retrieved from http://bmcmedresmethodol. biomedcentral.com/articles/10.1186/1471-2288-14-80

Urquhart, C. (2011). Meta-synthesis of research on information seeking behaviour. Information Research, 16(1). Retrieved from http://www.informationr.net/ir/16-1/paper455.html

Weed, M. (2005). Meta interpretation: A method for the interpretative synthesis of qualitative research. Qualitative Social Research, 6(1). Retrieved from www.qualitative-research.net/ index.php/fqs/ article/view/508/1096 